\title{
Silencing of $T B X 20$ gene expression in rat myocardial and human embryonic kidney cells leads to cell cycle arrest in G2 phase
}

\author{
PEIYAN LIU ${ }^{1,2}$, YUELING SUN ${ }^{1,3}$, GUANGBIN QIU $^{3}$, HONGKUN JIANG $^{4}$ and GUANGRONG QIU ${ }^{1}$ \\ ${ }^{1}$ Department of Medical Genetics, College of Basic Medical Science, China Medical University, Shenyang, Liaoning 110122; \\ ${ }^{2}$ Institute of Transfusion Medicine, Qingdao Blood Center, Qingdao, Shandong 266071; ${ }^{3}$ Department of Laboratory Medicine, \\ 202 Hospital of People's Liberation Army, Shenyang, Heping 110003; ${ }^{4}$ Department of Pediatrics, \\ The First Affiliated Hospital, China Medical University, Shenyang, Heping 110001, P.R. China
}

Received August 7, 2015; Accepted July 19, 2016

DOI: $10.3892 / \mathrm{mmr} .2016 .5660$

\begin{abstract}
Congenital heart diseases (CHDs) are the most common birth defects due to abnormal cardiac development. The T-box 20 (TBX20) gene is a member of the T-box family of transcription factors and encodes TBX20, which is essential for early heart development. In the present study, reduced TBX20 expression was observed in CHD tissue samples compared with normal tissues, and the function of TBX20 in Rattus norvegicus myocardial cells [H9c2(2-1)] and human embryonic kidney cells (HEK293) was investigated. TBX20 was silenced in H9c2 and HEK293 cells via transfection of small interfering RNA and short hairpin RNA duplexes, respectively, and TBX20 mRNA and protein levels were subsequently examined using reverse transcription-quantitative polymerase chain reaction (RT-qPCR) and western blot analysis. Cell proliferation was assessed using a cell counting kit and proliferating cell nuclear antigen expression was determined by western blotting. Analysis of cell apoptosis was achieved by annexin V-fluorescein isothiocyanate/propidium iodide staining and a fluorometric terminal deoxynucleotidyl transferase dUTP nick-end labeling system. Cell cycle analysis was achieved using fluorescence-activated cell sorting, and, an RT-qPCR array was used to profile the expression of $T B X 20$-related genes. Silencing of $T B X 20$ in $\mathrm{H} 9 \mathrm{c} 2$ and HEK 293 cells significantly inhibited cell proliferation, induced cell apoptosis and led to G2/M cell cycle
\end{abstract}

Correspondence to: Professor Guangrong Qiu, Department of Medical Genetics, College of Basic Medical Science, China Medical University, 77 Puhe Road, Shenyang North New Area, Shenyang, Liaoning 110122, P.R. China

E-mail: grqiu@mail.cmu.edu.cn

Professor Guangbin Qiu, Department of Laboratory Medicine, 202 Hospital of People's Liberation Army, 5 Guangrong Street, Shenyang, Heping 110003, P.R. China

E-mail: qiuguangbin@163.com

Key words: T-box 20, small-interfering RNA, cell proliferation, cell cycle arrest arrest. A reduction in cyclin B1 mRNA levels and an increase in cyclin-dependent kinase inhibitor 1B mRNA levels was observed, which indicated that cells were arrested in G2 phase. Concurrently, the mRNA levels of GATA binding protein 4 were increased in both cell lines, which may provide an explanation for the abnormal cardiac hypertrophy observed in patients with congenital heart disease. These results suggest that $T B X 20$ is required for heart morphogenesis, and inhibition of $T B X 20$ expression may lead to the suppression of cell proliferation and cell cycle arrest.

\section{Introduction}

Heart defects account for the majority of human birth defects and are the leading cause of birth defect-related cases of mortality (1). Congenital heart disease (CHD) is a defect in the structure of the heart and great vessels that is present at birth. Approximately 9 in 1,000 people are born with a congenital heart defect (2). The heritability of risk for CHD is estimated to be 55-65\%, however, both genetic and environmental factors are responsible for the onset of the disease (3-5). During fetal development, a series of events including cell growth, migration and programmed cell death results in the development of a well-formed heart at birth. Disruption of any one of these processes may result in a heart defect (6). It is therefore important to identify the genes that function to regulate this process of cardiac development.

The T-box 20 (TBX20) gene is a member of the T-box family of transcription factors that share a highly conserved DNA binding region (known as the T-box) and serve an essential role in early heart development (7-10), adult heart function (11) and CHD in humans (12-16). During heart morphogenesis, TBX20 coordinates cardiac cell proliferation and differentiation, and formation of cardiac chambers (8-10). Tbx20 knockout mice have been observed to exhibit arrested development at E9.0 and die at E10.5 (7), and increased Tbx20 expression leads to congenital atrial septal defects, patent foramen ovale and cardiac valve defects (14). One study involving heterozygous mutations of Tbx20 in adult mice, indicates that Tbx 20 haploinsufficiency is associated with left ventricular dilation, decreased heart wall thickness and contractile dysfunction (9). Ablation of Tbx20 in the adult mouse myocardium 
causes dilation of the cardiac chambers and lethality within 15 days (17). Mechanistically, TBX20 physically interacts with a number of major factors involved in the regulation of cardiac development, such as GATA binding protein 4 (GATA4) and NK2 homeobox 5 (NKX2-5) transcription factors $(9,14)$. Tbx20 also functions as a transcriptional repressor of T-box 2 (9) and ISL LIM homeobox 1 transcription factors (7) and is an activator of myocyte enhancer factor $2 \mathrm{C}(10)$. Therefore, TBX20 serves a crucial role in cardiac morphogenesis and functions by interacting with other genes and regulating downstream targets.

In the present study, the expression levels of $T B X 20$ were investigated in cardiac tissue samples derived from patients with sporadic types of CHD. Reduced TBX20 expression levels were observed in CHD tissue samples compared with normal tissues. To determine whether reduced TBX20 expression leads to inhibition of cell proliferation and cell cycle arrest, $T B X 20$ small-interfering RNAs (siRNAs) were transfected into H9c2(2-1) Rattus norvegicus myocardial cells. Additionally, TBX20 short-hairpin RNAs (shRNAs) were transfected into HEK293 human embryonic kidney cells to investigate the effects of TBX20 knockdown in human cells.

\section{Materials and methods}

Patient samples and cell lines. Informed consent from patients or guardians was first obtained prior to the collection of 24 cardiac tissue samples, which were provided by the Shengjing Hospital of China Medical University (Shenyang, China). This study received ethical approval from the local Medical Ethics Committee of China Medical University (Shenyang, China). Tissue specimens were obtained from the free wall of the left ventricle or atrial appendage in 12 patients with CHD (patient group; gestational age, GA: 14-38 weeks), and 12 age and gender-matched autopsies (control group; GA: 22-32 weeks) that exhibited no structural or hemodynamic abnormalities of the heart.

HEK293 human embryonic kidney cells and H9c2(2-1) Rattus norvegicus myocardial cells were purchased from the cell bank of Chinese Academy of Sciences (Shanghai, China). The cell lines were cultured in Dulbecco's modified Eagle's medium supplemented with $10 \%$ fetal bovine serum, and maintained in a humidified $5 \%(\mathrm{v} / \mathrm{v}) \mathrm{CO}_{2}$ incubator at $37^{\circ} \mathrm{C}$.

RNA isolation and reverse transcription-quantitative polymerase chain reaction $(R T-q P C R)$. Total RNA was extracted from cardiac tissue samples and cell lines using the TRIzol Reagent (Invitrogen; Thermo Fisher Scientific, Inc., Carlsbad, CA, USA) according to the manufacturer's instructions. cDNA was synthesized from $3 \mu \mathrm{g}$ of RNA using a Reverse Transcription system purchased from Promega (Beijing) Biotech Co., Ltd. (Beijing, China) and PCR was performed using $\beta$-actin as an internal control to analyze TBX20 mRNA expression in cardiac tissue samples and the primers listed in Table I. The relative expression levels of mRNA were determined using the optical density ratio (TBX20/ $\beta$-actin) using AlphaImager 2200 software (Bio-Rad Laboratories, Inc., Hercules, CA, USA). Analysis of TBX20 expression in cell lines by qPCR was achieved using the primers listed in Table I and was performed using an Applied Biosystems
7500 Real-Time PCR system (Thermo Fisher Scientific, Inc., Foster City, CA, USA). Reaction mixtures consisted of $12.5 \mu \mathrm{l}$ SYBR ${ }^{\circledR}$ Green PCR Master mix (Applied Biosystems; Thermo Fisher Scientific, Inc.), $0.5 \mu \mathrm{l}$ primer $(10 \mathrm{mM} / \mathrm{l})$ and $1 \mu \mathrm{l} \mathrm{cDNA}$. Thermal cycling conditions consisted of an initial denaturation step of $95^{\circ} \mathrm{C}$ for $10 \mathrm{~min}$, followed by 40 cycles of denaturation at $95^{\circ} \mathrm{C}$ for $10 \mathrm{sec}$ and annealing and extension at $60^{\circ} \mathrm{C}$ for $1 \mathrm{~min}$. Fluorescence measurements were collected at the end of each extension step. The quantification cycles $\left(\mathrm{C}_{\mathrm{q}}\right)$ were then determined and the relative concentrations of mRNA were calculated and normalized against the levels of $\beta$-actin or glyceraldehyde 3-phosphate dehydrogenase (Gapdh) expression in each sample (18). Reactions were performed with non-template controls. Melting curve analyses were conducted following completion of the thermal cycling program using a temperature ramp that increased the temperature from $45-95^{\circ} \mathrm{C}$ at a rate of $0.5^{\circ} \mathrm{C}$ every $2 \mathrm{sec}$. During this time, fluorescence signals were monitored continuously to determine the specificity of PCR primers, which was subsequently confirmed by conventional gel electrophoresis. For each sample, reactions were conducted in triplicate to ensure the reproducibility of the results.

Western blotting analysis. Total protein was extracted from 24 frozen cardiac tissue samples and cultured cells using a lysis buffer containing protease inhibitors (KeyGen Biotechnology, Co., Ltd., Nanjing, China). Protein concentrations of sample lysates were determined using a bicinchoninic acid kit (KeyGen Biotechnology, Co., Ltd.) according to the manufacturer's instructions. Samples $(20 \mu \mathrm{g})$ were denatured by adding $5 \mathrm{X}$ SDS-PAGE sample loading buffer (Beyotime Institute of Biotechnology, Jiangsu, China) and incubating for $10 \mathrm{~min}$ at $95^{\circ} \mathrm{C}$. Sample proteins were then separated by $12 \%$ SDS-PAGE and electroblotted onto a polyvinylidene fluoride membrane. Membranes were blocked using non-fat dry milk $(5 \%)$ in phosphate-buffered saline (PBS, $0.05 \%$ ) and $0.05 \%$ Tween-20 at room temperature for $2 \mathrm{~h}$. This was followed by incubation with rabbit anti-TBX20 (catalog no. sc-134061) or rabbit anti- $\alpha$-tubulin (catalog no. sc-5546) at a dilution of 1:500 (Santa Cruz Biotechnology, Inc., Dallas, TX, USA) overnight at $4^{\circ} \mathrm{C}$. The following day, membranes were washed three times with PBS containing 0.05\% Tween-20 for $15 \mathrm{~min}$, and incubated with the secondary horseradish peroxidase (HRP)-conjugated goat anti-rabbit IgG antibody $(1: 2,000$; catalog no. sc-2004; Santa Cruz Biotechnology, Inc.) for $2 \mathrm{~h}$ at room temperature. Protein bands were visualized using enhanced chemiluminescence detection, and the membranes were exposed to X-ray film. $\alpha$-Tubulin was used as the internal control. The relative expression levels of protein were determined using the optical density ratio (TBX20/ $\alpha$-Tubulin) using AlphaImager 2200 software (Bio-Rad Laboratories, Inc.).

Design of shRNA and siRNA duplexes. shRNA and siRNA duplexes targeting $T B X 20$ were designed according to the characterization of the $T B X 20$ gene by Hammer et al (19). $T B X 20$ has two splice variants, $T B X 20 A$ and $T B X 20 B$; both isoforms share six identical exons, while $T B X 20 A$ has two additional exon sequences. Therefore, shRNA and siRNA duplexes used for the purposes of this study, were designed to target $T B X 20 B$. Similarly, rat $T b \times 20$ has two splice variants, $T b \times 20 a$ and $T b \times 20 b$. shRNAs that target human 
Table I. Details of primer sequences used for reverse transcription-quantitative polymerase chain reaction.

\begin{tabular}{|c|c|c|c|}
\hline Species & Primers & Sequence $\left(5^{\prime}-3^{\prime}\right)$ & Product size (bp) \\
\hline \multirow[t]{9}{*}{ Homo sapiens } & TBX20 (1) & F: AGGAGGCGACGGAGAACA & 286 \\
\hline & & R: CTGCCCGACTTGGTGATG & \\
\hline & $T B X 20(2)$ & $\begin{array}{l}\text { F: CATCCAGATTCTCCTTTTACCG } \\
\text { R: TTCAGCTTCGTTATCAGTTGATTC }\end{array}$ & 272 \\
\hline & $P 27$ & $\begin{array}{l}\text { F: AGCGACCTGCAACCGACGATTC } \\
\text { R: GGCCAGGCTTCTTGGGCGTC }\end{array}$ & 120 \\
\hline & Cyclin B1 & $\begin{array}{l}\text { F: TCTGGATAATGGTGAATGGACA } \\
\text { R: CGATGTGGCATACTTGTTCTTG }\end{array}$ & 157 \\
\hline & $N K X 2-5$ & $\begin{array}{l}\text { F: CAAGTGTGCGTCTGCCTTT } \\
\text { R: GCGCACAGCTCTTTCTTTTC }\end{array}$ & 105 \\
\hline & GATA4 & $\begin{array}{l}\text { F: CGGAAGCCCAAGAACCTGA } \\
\text { R: CTGCTGTGCCCGTAGTGAG }\end{array}$ & 176 \\
\hline & $\beta$-actin (1) & $\begin{array}{l}\text { F: CTCTTCCAGCCTTCCTTCCT } \\
\text { R: CACCTTCACCGTTCCAGTTT }\end{array}$ & 511 \\
\hline & $\beta$-actin (2) & $\begin{array}{l}\text { F: ATAGCACAGCCTGGATAGCAACGTAC } \\
\text { R: CACCTTCTACAATGAGCTGCGTGTG }\end{array}$ & 158 \\
\hline \multirow[t]{6}{*}{ Rattus norvegicus } & $\operatorname{Tbx} 20$ & $\begin{array}{l}\text { F: AGCAGTCACAGCCTACCAGA } \\
\text { R: ATGCCAAGGAAGACGAGTT }\end{array}$ & 187 \\
\hline & $p 27$ & $\begin{array}{l}\text { F: GCGGCAAGAGAGGCGAGGC } \\
\text { R: CGGAAGGCTTGGGGTGCTCG }\end{array}$ & 129 \\
\hline & Cyclin bl & $\begin{array}{l}\text { F: GGCGCTCAGGGTCACTAGGAACA } \\
\text { R: GGGGTATTCTTGACTGTTCGCTGAC }\end{array}$ & 173 \\
\hline & $N k \times 2-5$ & $\begin{array}{l}\text { F: GATGCCACAGGGCAATTC } \\
\text { R: TCTCCTAAAGGTGGGAGTCG }\end{array}$ & 104 \\
\hline & Gata4 & $\begin{array}{l}\text { F: CACTATGGGCACAGCAGCTCC } \\
\text { R: TTGGAGCTGGCCTGCGATGTC }\end{array}$ & 186 \\
\hline & Gapdh & $\begin{array}{l}\text { F: CCCACTCGTAGCCCCTCTG } \\
\text { R: TGCTGAGTATGTCGTGGAGT }\end{array}$ & 289 \\
\hline
\end{tabular}

TBX20 (1) and $\beta$-actin (1) were used for cardiac tissue samples, whereas TBX20 (2) and $\beta$-actin (2) are the primers of real time-PCR in cell lines. TBX20, T-box 20; P27, cyclin-dependent kinase inhibitor (CDKI) 1B; NKX2-5, NK2 homeobox 5; GATA4, GATA binding protein 4; bp, base pair; F, forward; $R$, reverse.

$T B X 20 B$ (Ensembl Transcript ID: ENST00000492961; www.ensembl.org) and siRNAs that targeted rat $T b \times 20 b$ (Ensembl Transcript ID: ENSRNOT00000064783) were designed by GenePharma Co., Ltd., (Shanghai, China). A total of three green-fluorescent protein (GFP)-tagged shRNA sequences were designed to target human TBX20 mRNA transcripts at the nucleotide positions 845-864, 1094-1113, and 1152-1171, and three siRNA duplexes were designed to target rat $T b \times 20$ mRNA transcripts at nucleotide positions 752-772, 1042-1062, and 1089-1109. Negative control shRNA (NC-shRNA) and siRNA (NC-siRNA) duplexes consisted of random sequences that do not target any known mammalian genes. siRNA duplexes were chemically synthesized, and 1.0 optical density $(20 \mu \mathrm{M} / \mathrm{l})$ of NC-siRNA was labeled with the carboxyfluorescin (FAM) fluorophore (GenePharma Co., Ltd.). NC-shRNA duplexes were cloned into GFP-tagged vectors.

Transfection of siRNA and shRNA into mammalian cells. Transfection of shRNA and siRNA duplexes into HEK293 and
H9c2 cells was achieved using the FuGENE ${ }^{\circledR}$ HD Transfection Reagent (Roche Diagnostics, Basel, Switzerland) according to the manufacturer's instructions. At $24 \mathrm{~h}$ post-transfection with GFP-labeled NC-shRNA or FAM-labeled NC-siRNA, cells were visualized using an inverted fluorescence microscope with a digital charged-coupled device imaging system (IX71/DP70; Olympus Corporation, Tokyo, Japan) in order to determine transfection efficiency.

Cell proliferation assay. Cell viability was determined using a cell counting kit (CCK-8; Beyotime Institute of Biotechnology). Cells (5x10\%/well) were seeded onto 96 -well flat-bottom plates one day prior to transfection. At 24, 48, 72, and $96 \mathrm{~h}$ post-transfection, $10 \mu \mathrm{l}$ CCK- 8 was added to each well, and cells were incubated for a further $2 \mathrm{~h}$. Sample absorbance was proportional to the number of living cells and was measured using a microplate reader (Bio-Rad Laboratories, Inc., Hercules, CA, USA) at $450 \mathrm{~nm}$. The rate of cell proliferation inhibition was calculated using the following formula: Rate of cell proliferation inhibition $=[$ (Average absorbance 
of the control group-average absorbance of the experimental group)/average absorbance of the control group]x $100 \%$.

Cells harvested at $96 \mathrm{~h}$ post-transfection were subject to western blot analysis for proliferating cell nuclear antigen (PCNA) using a mouse anti-PCNA antibody (1:500; catalog no. sc-53407; Santa Cruz Biotechnology, Inc.) and a goat anti-mouse IgG-HRP secondary antibody $(1: 2,000$; catalog no. sc-2005; Santa Cruz Biotechnology, Inc.), which is a reliable assay for the determination of cell proliferation. This was performed using the same procedures described previously.

Cell apoptosis assay. In order to detect early cell apoptosis, annexin V-fluorescein isothiocyanate (FITC)/propidium iodide (PI) staining (BD Biosciences, Franklin Lakes, NJ, USA) and flow cytometry analysis were performed according to the manufacturer's instructions. Briefly, cells $\left(5 \times 10^{5}\right.$ cells/well) were seeded onto six-well flat-bottom plates. At $48 \mathrm{~h}$ post-transfection, cells were trypsinized, resuspended in binding buffer and incubated in $5 \mu \mathrm{l}$ annexin V-FITC and $5 \mu 1 \mathrm{PI}$ for $15 \mathrm{~min}$ at $25^{\circ} \mathrm{C}$ in the dark, prior to flow cytometry analysis. Early FITC-stained apoptotic cells were represented in the lower-right quadrant of the fluorescence-activated cell sorting histogram.

In order to detect late cell apoptosis, the DeadEnd ${ }^{\mathrm{TM}}$ Fluorometric TUNEL System (Promega Corporation, Madison, WI, USA) was used according to the manufacturer's instructions. Briefly, adherent cells in two-well chamber slides were fixed with $4 \%$ formaldehyde and treated with $0.2 \%$ Triton X-100. Following equilibration at room temperature, cells were incubated in buffer containing nucleotides and the terminal deoxynucleotidyl transferase enzyme for $1 \mathrm{~h}$. Cells were then stained with PI for 5 min in the dark and visualized under the microscope. Cells were considered to be apoptotic if they had TUNEL-positive nuclei and morphological features of cell death, including cell shrinkage, fragmentation and regions of dense chromatin condensation. The apoptotic index was defined as the percentage of TUNEL-positive cells in each well, from three random fields of view (magnification, $\mathrm{x} 20$ ).

Cell cycle analysis. Cell cycle analysis was achieved using PI staining and flow cytometry (FACSCalibur flow cytometer; BD Biosciences). Briefly, cells were seeded onto six-well plates and transfected with siRNA or shRNA using the aforementioned procedures. At 48 or $96 \mathrm{~h}$ post-transfection, cells were harvested and fixed by adding $70 \%$ ethanol and incubating for $12 \mathrm{~h}$ at $-20^{\circ} \mathrm{C}$. Cells were then stained with PI in a PBS solution containing RNase (KeyGen Biotechnology, Co., Ltd.) and analyzed by flow cytometry.

In order to determine the expression levels of factors involved in regulating cell cycle progression, the mRNA levels of cyclin B1, P27, P16 and P21 were assessed by RT-qPCR and normalized to $\beta$-actin or Gapdh, as described above. The expression levels of these genes were determined in cells harvested at 48 or $96 \mathrm{~h}$ post-transfection using the aforementioned procedures.

Statistical analysis. The data are expressed as the mean \pm standard deviation and differences between the means were evaluated using analysis of variance and the Student's $t$-test with SPSS software (version 16.0; SPSS Inc., Chicago, IL, USA). $\mathrm{P}<0.05$ was considered to indicate a statistically significant difference.

\section{Results}

TBX20 expression is decreased in CHD cardiac tissues. The mRNA expression levels of $T B X 20$ were significantly reduced in cardiac tissues from CHD patients compared to cardiac tissues from normal controls $(\mathrm{P}=0.023$; Fig. 1A), which was confirmed by western blotting analysis ( $\mathrm{P}=0.031$; Fig. 1B).

TBX20 expression is reduced following transfection of $H 9 c 2$ and HEK293 cells with TBX20 siRNA and shRNA duplexes, respectively. At $24 \mathrm{~h}$ post-transfection with fluorescently-labelled TBX2O siRNA and shRNA duplexes, the transfection efficiency was determined using fluorescence microscopy by comparing optical microscope images of identical fields of view. Following confirmation of a high transfection efficiency for TBX20 siRNA and shRNA duplexes in H9c2 (80\%) and HEK293 (90\%) cells, respectively, the mRNA and protein expression levels of TBX20 were determined by RT-qPCR and western blotting analysis. At 48 h post-transfection with Tbx20-1089-siRNA, H9c2 cells exhibited a significant decrease $(\mathrm{P}=0.021$ and $\mathrm{P}=0.011)$ in the expression levels of TBX20 mRNA and protein compared with normal controls (Fig. 2A and B). Consistent with these observations, at $96 \mathrm{~h}$ following transfection of HEK293 cells with TBX20-845-shRNA, the expression levels of TBX20 mRNA and protein were significantly reduced $(\mathrm{P}=0.018$ and $\mathrm{P}=0.012$, respectively; Fig. $2 \mathrm{C}$ and $\mathrm{D}$ ). These results indicate that Tbx20-1089-siRNA and TBX20-845-shRNA duplexes inhibit TBX20 expression in H9c2 and HEK293 cells, respectively.

TBX20 inhibition represses cell proliferation in $\mathrm{H} 9 \mathrm{c} 2$ and HEK293 cells. To investigate the association between TBX20 inhibition and H9c2 and HEK293 cell proliferation, cell viability was assessed using a CCK-8 assay following transfection of cells with TBX20 siRNA and shRNA duplexes, respectively. Compared with NC-siRNA-transfected controls, a significant time-dependent decrease in cell proliferation rates were observed at 72 and $96 \mathrm{~h}(48.3 \pm 0.036$ and $51.8 \pm 0.110 \%$, respectively) following transfection of $\mathrm{H} 9 \mathrm{c} 2$ cells with Tbx20-1089-siRNA ( $\mathrm{P}<0.01$; Fig. 3A). A significant time-dependent reduction in cell proliferation rates were also observed in HEK293 cells at 72, 96 and 120 h $(57.3 \pm 0.049$, $42.3 \pm 0.034$ and $43.3 \pm 0.020 \%$, respectively) following transfection with TBX20-845-shRNA ( $\mathrm{P}<0.01$; Fig. 3B).

The putative repressive effect of $T B X 20$ inhibition on cell proliferation was then investigated by western blotting analysis for PCNA, which is only expressed in proliferating cells (20). A significant reduction in PCNA protein expression levels was observed in $\mathrm{H} 9 \mathrm{c} 2$ cells at $96 \mathrm{~h}$ post-transfection with Tbx20-1089-siRNA ( $\mathrm{P}=0.017$; Fig. 3C). In addition, a significant reduction in PCNA protein expression levels was observed in HEK293 cells at $96 \mathrm{~h}$ post-transfection with TBX20-845-shRNA ( $\mathrm{P}=0.022$; Fig. 3D). These results are consistent with those obtained from the CCK-8 assays, which suggests that $T B X 20$ inhibition suppresses the proliferation of H9c2 and HEK293 cells. 
A
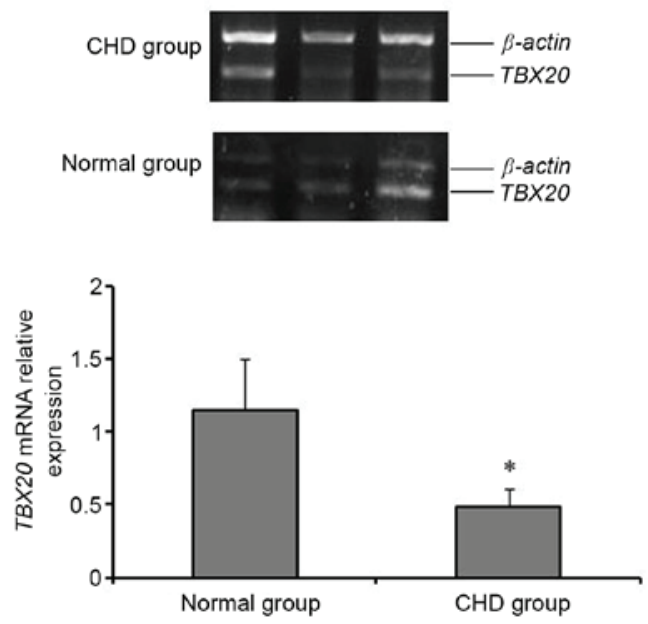

B
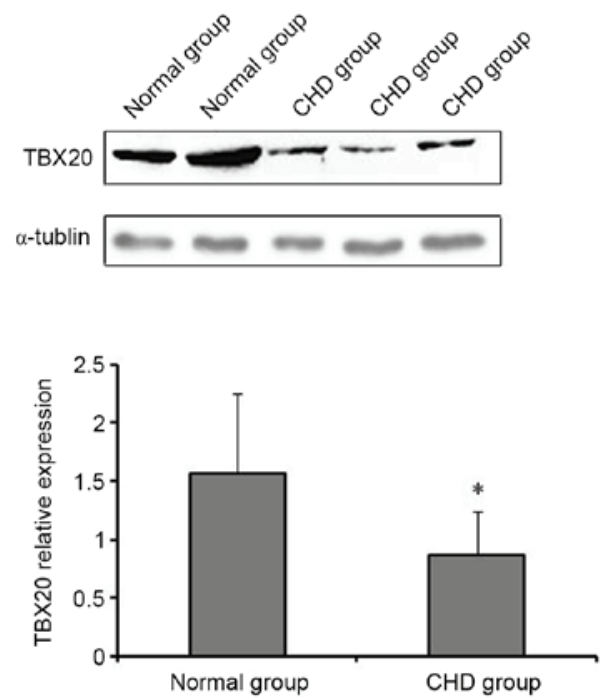

Figure 1. TBX20 expression is reduced in CHD cardiac tissues compared with normal controls. (A) The mRNA expression of TBX20 was detected using reverse transcription-quantitative polymerase chain reaction in $12 \mathrm{CHD}$ patients and 12 normal controls (TBX20 mRNA was normalized against $\beta$-actin). (B) The expression of TBX20 protein was detected by western blotting in 12 CHD patients and 12 normal controls (TBX20 protein levels were normalized against $\alpha$-tubulin). Data are expressed as the mean \pm standard deviation from independent experiments performed in triplicate ${ }^{*} \mathrm{P}<0.05$ vs. normal. CHD, congenital hear disease; TBX20, T-box 20.

A

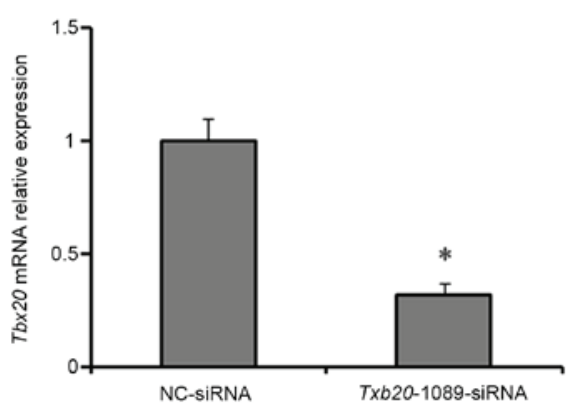

$\mathrm{C}$

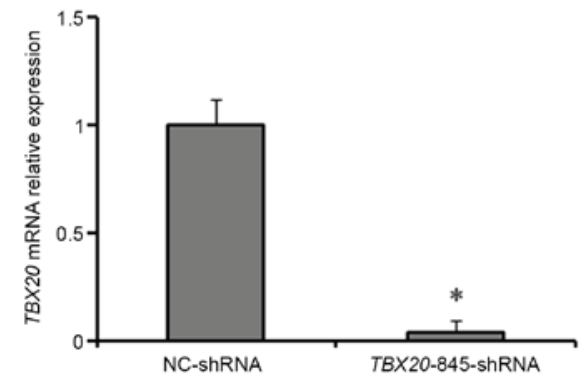

B

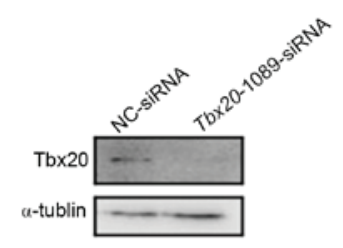

$\mathrm{D}$
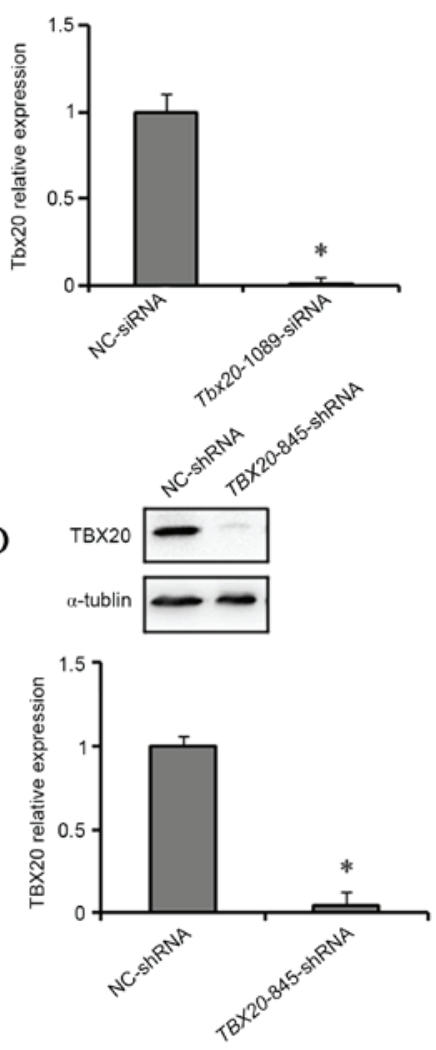

Figure 2. TBX20 mRNA and protein expression is significantly reduced following transfection of TBX20 siRNA and shRNA duplexes in H9c2 and HEK293 cells, respectively. The expression levels of Tbx20 (A) mRNA and (B) protein in H9c2 cells, $48 \mathrm{~h}$ following transfection with Tbx20-1089-siRNA and NC-siRNA controls. The expression levels of TBX20 (C) mRNA and (D) protein in HEK293 cells $96 \mathrm{~h}$ following transfection with TBX20-845-shRNA and NC-shRNA controls. " $\mathrm{P}<0.05$ vs. controls. TBX20, T-box 20; siRNA, small-interfering RNA; shRNA, short-hairpin RNA; NC, normal control. 

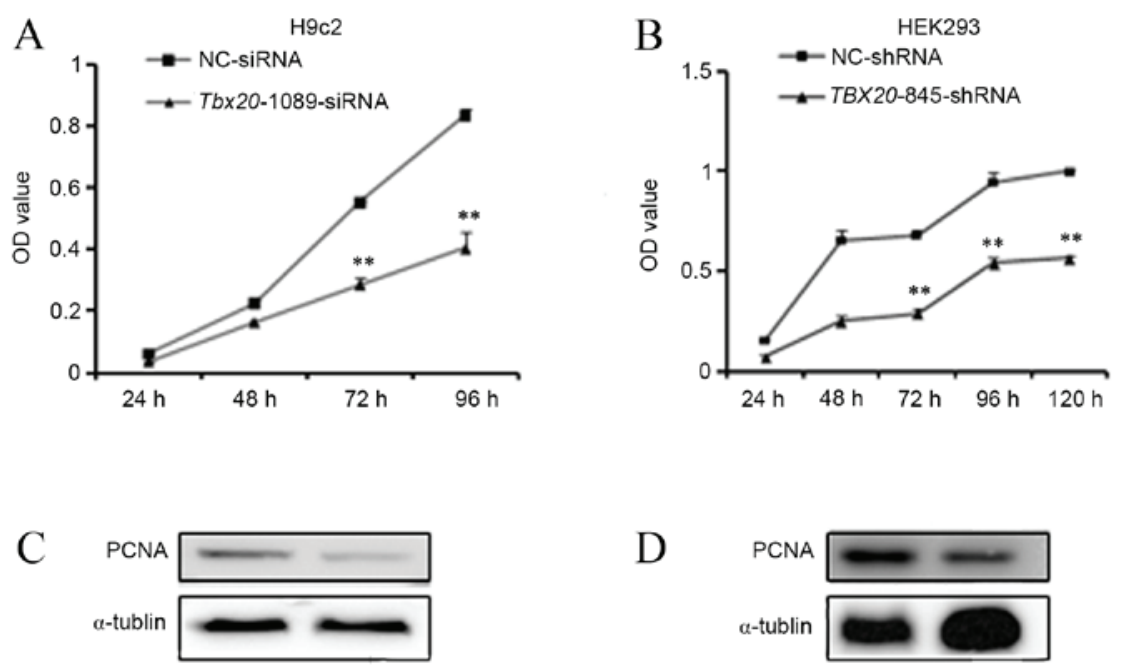

$\mathrm{D}$
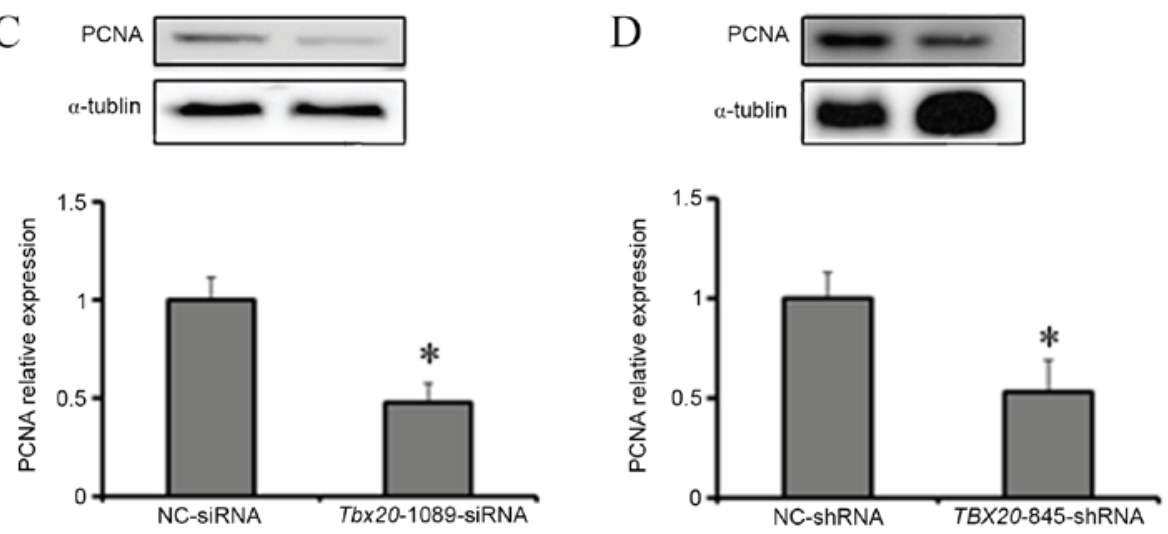

Figure 3. TBX2O inhibition suppresses H9c2 and HEK293 cell proliferation. Cell counting kit-8 assay analysis of (A) H9c2 cells at 24, 48, 72 and 96 h post-transfection with Tbx20-1089-siRNA and (B) HEK293 cells at 24, 48, 72, 96 and 120 h post-transfection with TBX20-845-shRNA. Western blotting analysis of PCNA expression in (C) H9c2 cells $96 \mathrm{~h}$ post-transfection with Tbx20-1089-siRNA and NC-siRNA controls, and (D) HEK293 cells $96 \mathrm{~h}$ post-transfection with TBX20-845-shRNA and NC-shRNA controls. ${ }^{*} \mathrm{P}<0.05$ and ${ }^{* *} \mathrm{P}<0.01$ vs. controls. TBX20, T-box 20; siRNA, small-interfering RNA; shRNA, short-hairpin RNA; NC, normal control; PCNA, proliferating cell nuclear antigen.

TBX2O inhibition induces cell apoptosis in $H 9 c 2$ and HEK293 cells. Annexin V-FITC/PI staining was performed to detect early cell apoptosis. Compared with negative controls, the percentage of early apoptotic cells was observed to increase significantly in $\mathrm{H} 9 \mathrm{c} 2$ cells transfected with Tbx20-1089-siRNA ( $\mathrm{P}=0.027 ; 7.73 \pm 0.9 \%)$, and in HEK293 cells transfected with TBX20-845-shRNA $(\mathrm{P}=0.034$; 12.16 $\pm 2.1 \%$; Fig. $4 \mathrm{~A}$ and B).

TUNEL staining was then performed in order to determine late cell apoptosis. As demonstrated in Fig. 4C and D, a significant increase in the percentage of late apoptotic cells was observed in H9c2 cells transfected with Tbx20-1089-siRNA $(\mathrm{P}=0.028 ; 17.5 \pm 0.013 \%)$ and in HEK293 cells transfected with TBX20-845-shRNA $(\mathrm{P}=0.024 ; 10.5 \pm 0.15 \%)$. These results suggest that $T B X 20$ inhibition may induce apoptosis of $\mathrm{H} 9 \mathrm{c} 2$ and HEK293 cells.

TBX20 inhibition leads to cell cycle arrest in G2 phase of $H 9 c 2$ and HEK293 cells. To investigate the effects of $T B X 20$ inhibition on cell cycle progression, PI staining and flow cytometry analyses were conducted to examine the cell cycle phases of H9c2 and HEK293 cells transfected with TBX2O siRNA and shRNA duplexes respectively. As demonstrated in Table II and Fig. 5A and B, the percentage of cells in the $\mathrm{G} 2 / \mathrm{M}$ phase were significantly increased in Tbx20-1089-siRNA-transfected H9c2 cells $(\mathrm{P}=0.036$; $6.38 \pm 0.78 \%$ ) and $T B X 20-845$-shRNA-transfected HEK 293 cells $(\mathrm{P}=0.025 ; 7.86 \pm 1.56 \%)$ compared with negative controls.
To investigate the mechanisms of cell cycle arrest following TBX20 inhibition, RT-qPCR analysis was used to detect the expression of a number of important cell cycle regulators including, cyclin $B 1, P 27, P 21$ and $P 16$. Compared with negative controls, at $48 \mathrm{~h}$ post-transfection of H9c2 cells with Tbx20-1089-siRNA, Tbx20 inhibition resulted in a significant reduction in the expression of cyclin B1 mRNA expression levels ( $\mathrm{P}=0.003$; Fig. 5C), with a concomitant significant increase in the expression levels of $p 27$ ( $\mathrm{P}=0.015$; Fig. 5D), and no considerable alterations in $p 16$ and $p 21$ expression levels $(\mathrm{P}=0.23$; Fig. $5 \mathrm{E}$ and $\mathrm{F})$. Similarly, at $96 \mathrm{~h}$ following transfection of HEK293 cells with TBX20-845-shRNA, the mRNA expression levels of cyclin $B 1$ were significantly reduced $(\mathrm{P}=0.026$; Fig. $5 \mathrm{C})$, $P 27$ expression levels were significantly increased $(\mathrm{P}=0.006$; Fig. 5D), and no notable alterations in $P 16$ and $P 21$ expression levels were observed when compared with negative controls $(\mathrm{P}=0.38$; Fig. 5E and $\mathrm{F})$.

TBX20 inhibition upregulates GATA4 mRNA expression in H9c2 and HEK293 cells. In order to investigate the role of TBX2O in heart development, the mRNA expression levels of GATA4 and NKX2-5 were determined in $\mathrm{H} 9 \mathrm{c} 2$ and HEK 293 cells following transfection with TBX20-siRNA and shRNA duplexes respectively. As demonstrated in Fig. 6A and B, the mRNA expression levels of Gata4 were significantly increased $(\mathrm{P}=0.001)$ within $\mathrm{H} 9 \mathrm{c} 2$ cells $48 \mathrm{~h}$ following transfection with Tbx20-1089-siRNA compared 
A

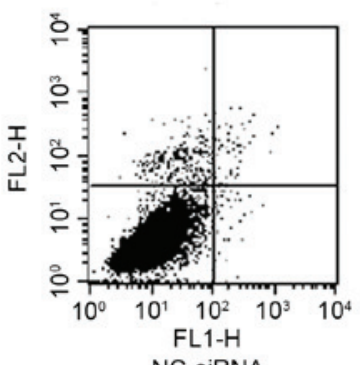

B

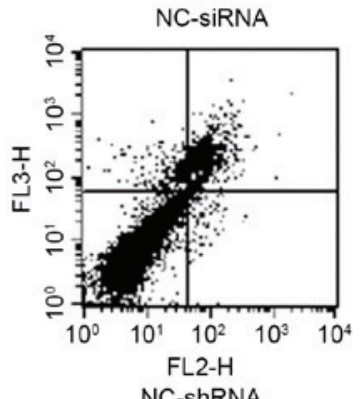

$\mathrm{C}$

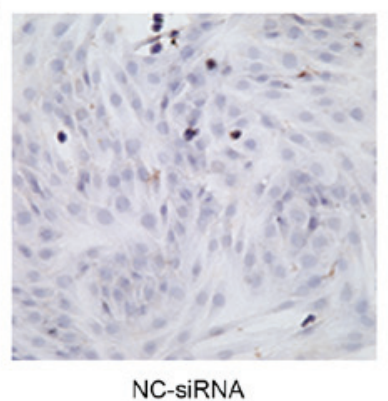

$\mathrm{D}$

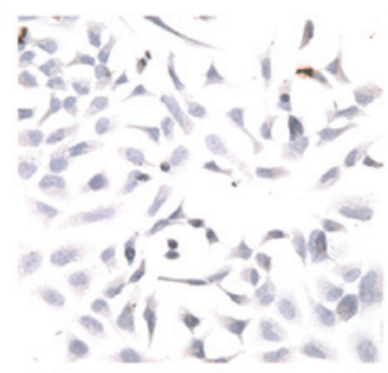

NC-shRNA
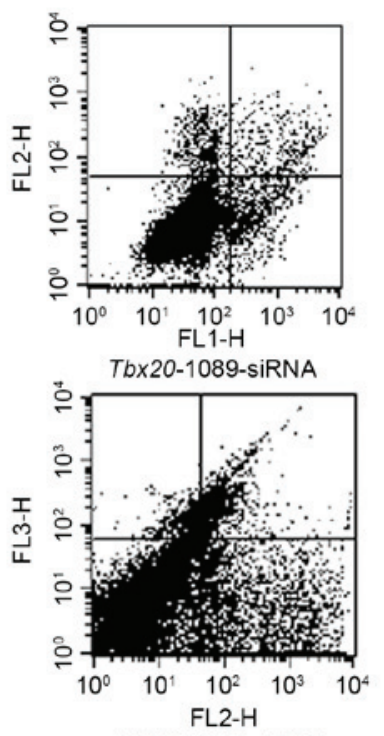

TBX20-845-shRNA

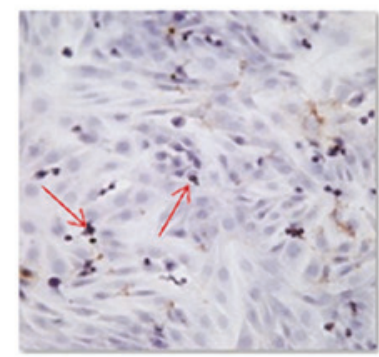

Tbx20-1089-siRNA

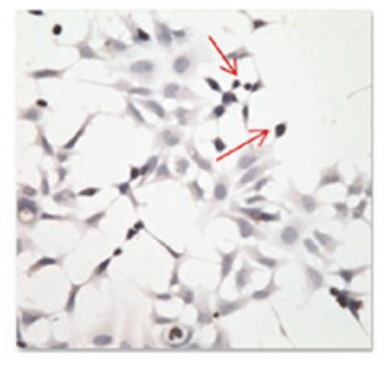

TBX20-845-shRNA

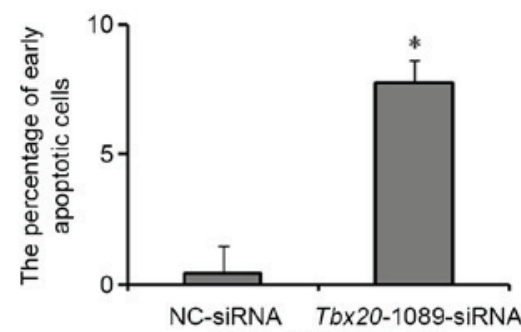

$\mathrm{Al}(\mathrm{H} 9 \mathrm{c} 2)=7.73 \% \pm 0.9$

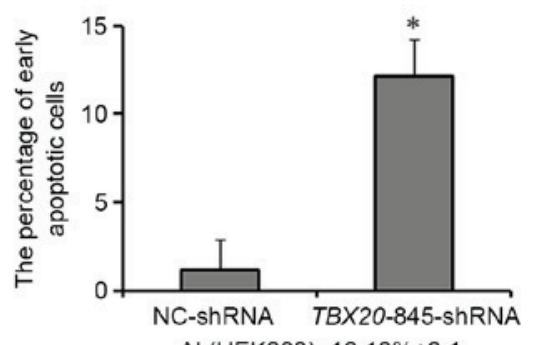

$\mathrm{Al}(\mathrm{HEK} 293)=12.16 \% \pm 2.1$
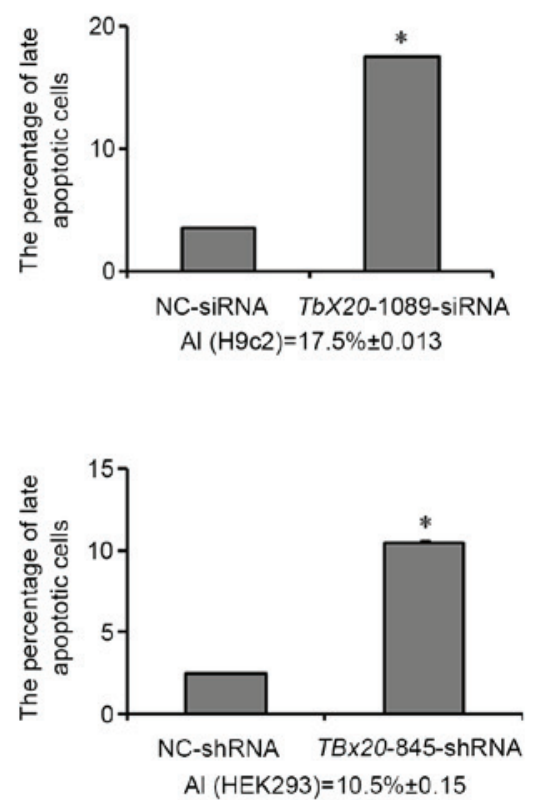

Figure 4. TBX20 inhibition induces cell apoptosis in H9c2 and HEK293 cells. Annexin V-fluorescein isothiocyanate/propidium iodide staining of (A) H9c2 cells following transfection with Tbx20-1089-siRNA and NC-siRNA controls, and (B) HEK293 cells following transfection with TBX20-845-shRNA and NC-shRNA controls. Terminal deoxynucleotidyl transferase staining of (C) H9c2 cells transfected with Tbx20-1089-siRNA and (D) HEK293 cells transfected with TBX20-845-shRNA. Magnification, x20. Red arrows indicate apoptotic bodies. " $\mathrm{P}<0.05$ vs. controls. TBX20, T-box 20; siRNA, small-interfering RNA; shRNA, short-hairpin RNA; NC, normal control.

with negative controls, whereas no significant alterations in $N k x 2-5$ expression levels were observed. Similarly, the expression levels of GATA4 mRNA were significantly increased $(\mathrm{P}=0.012)$ in HEK293 cells $96 \mathrm{~h}$ following transfection with $T B X 20-845$-shRNA and no notable alterations in $N K X 2-5$ expression levels were observed, when compared with controls $(\mathrm{P}=0.09$; Fig. $6 \mathrm{~A}$ and $\mathrm{B})$.

\section{Discussion}

During the process of human heart morphogenesis, both cardiomyocyte proliferation and enlargement contribute to postnatal heart growth (15). Notably, targeted disruption of cardiomyocyte proliferation at mid-gestation, leads to hypoplastic ventricular walls and impaired trabeculation (16). Therefore, normal cardiomyocyte proliferation is necessary to support the growth and development of the postnatal human heart. The T-box family of transcription factors serve critical functional roles in embryonic development and organogenesis including, cell type specification, tissue patterning and morphogenesis (21). In particular, the endocardium, myocardium and epicardium of the developing heart express TBX20, which suggests that TBX20 has numerous roles in cardiac development (22). The results of the present study suggest that TBX20 is a key mediator of cell proliferation, particularly cell cycle progression.

$T B X 20$ is a dose-sensitive regulator. In zebrafish and mouse models, knockout or knockdown of $T b \times 20$ is 
Table II. Percentage of H9c2 and HEK293 cells in different cell cycle phases following silencing of TBX20 expression.

\begin{tabular}{lccc}
\hline Group & G0/G1 phase $(\%)$ & S phase $(\%)$ & G2/M phase $(\%)$ \\
\hline H9c2-NC-siRNA & $75.99 \pm 1.33$ & $20.78 \pm 1.44$ & $3.22 \pm 0.99$ \\
H9c2-Tbx20-1089-siRNA & $67.69 \pm 0.83$ & $24.95 \pm 1.03$ & $6.38 \pm 0.78^{\mathrm{a}}$ \\
HEK293-NC-shRNA & $67.81 \pm 0.24$ & $31.11 \pm 1.54$ & $1.08 \pm 1.30$ \\
HEK293-TBX20-845-shRNA & $62.33 \pm 1.92$ & $29.82 \pm 3.47$ & $7.86 \pm 1.56^{\mathrm{a}}$ \\
\hline
\end{tabular}

Results are presented as mean \pm standard deviation. ${ }^{a} \mathrm{P}<0.05$ vs. NC controls. TBX20, T-box 20; siRNA, small-interfering RNA; shRNA, short-hairpin RNA; NC, negative control.

associated with abnormal heart cyclization, right ventricular dysplasia, severe damage of the outflow tract and disordered chamber differentiation, which suggests that maintaining normal $T b \times 20$ expression is critical for normal heart development $(7-10,23)$.

In the present study, the mRNA and protein expression levels of TBX20 in CHD patients were significantly lower than normal controls, which is consistent with previous animal studies (7-10,23). Therefore, it was hypothesized that this low level of TBX20 expression may be insufficient to maintain normal heart development in CHD patients and therefore be responsible for heart malformations. In contrast, Hammer et al (19) reported that $T B X 20$ expression was increased in patients with tetralogy of fallot. However, this may due to the study population and sample size, as this was a German study performed on 13 patients and 6 healthy controls.

During the heart development process, the number of cardiomyocytes increases due to mitosis and heart volume increases to support the rising hemodynamic load. Therefore, the ordered proliferation of cardiomyocytes is essential for normal heart development (15). A number of studies have confirmed that a reduction in the proliferation rate of fetal rat cardiomyocytes results in thinning of the myocardial compact layer and derangement of the heart trabeculae, which leads to cardiac septal defects as well as other structural deformities $(7,16,22)$.

The results of the present study demonstrate that $T B X 20$ participates in cardiomyocyte proliferation, which is consistent with previous mouse studies $(7,22)$. Additionally, the results provide evidence of a possible mechanism by which $T B X 20$ may regulate cardiomyocyte proliferation. Cyclin B1 is the primary activator of cyclin-dependent kinase 1 (CDK1). Through complex formation with CDK1, cyclin B1 controls the $\mathrm{G} 2 / \mathrm{M}$ transition during cell cycle progression $(24,25), P 27$ is a member of the kinase-inhibiting protein 1 family and controls $\mathrm{G} 2 / \mathrm{M}$ transition by repressing CDK1 (26,27). In the present study, transfection of siRNA and shRNA duplexes targeting TBX20 in rat myocardial cells and human embryonic kidney cells respectively, was associated with a significant reduction in the expression levels of cyclin B1 mRNA and a significant increase in P27 mRNA expression levels. Through the inactivation of CDK1, this decrease in cyclin $B 1$ and increase in $P 27$ expression was hypothesized to have lead to cell cycle arrest in G2, thereby blocking mitotic division and inhibiting cell proliferation.
However, it is unclear whether $T B X 20$ regulates cyclin $B 1$ and $P 27$ through direct or indirect mechanisms. Future research is necessary to clarify this further.

In addition to an adequate number of cardiomyocytes, normal heart development requires correct cardiomyocyte differentiation and maturation. GATA4 and NKX2-5 can be detected at an early stage of heart development, and regulate the differentiation and maturation of cardiomyocytes by interacting with myocyte enhancer factor 2, serum response factor, and atrial natriuretic factor (28-33). GATA4 and NKX2-5 are dosage-sensitive regulators of cardiac morphogenesis, and insufficient or excessive expression may result in a hypoplastic heart or abnormal cardiac hypertrophy (34-40). In the present study, TBX20 inhibition upregulated GATA4 mRNA expression levels in rat myocardial cells, and had no effects on NKX2-5 mRNA expression, which suggested that TBX20 may participate in cardiomyocyte differentiation and maturation. Combined with the decreased expression of TBX20 in cardiac tissue samples from CHD patients, this may partially explain abnormal cardiac hypertrophy observed in some CHD patients. The functions of TBX20 and GATA4 have been studied extensively in early cardiac cells $(8,9,15,35,41)$; however, the results of the present study demonstrate that TBX20 may additionally regulate the expression of GATA4 in human kidney cells. This may be due to the presence of analogous signaling pathways for heart and kidney development. The present results therefore provide novel evidence to suggest that TBX20 and GATA4 may serve a functional role in human kidney development, which should be investigated further using in vivo methodologies.

In conclusion, the results of the present study identified reduced TBX20 expression in cardiac tissues samples, and silencing of TBX20 in H9c2 and HEK293 cells significantly inhibited cell proliferation and induced cell apoptosis and $\mathrm{G} 2 / \mathrm{M}$ cell cycle arrest. A reduction in TBX20 expression was associated with a significant decrease in cyclin Bl expression and a significant increase in $P 27$ expression, which may have resulted in the observed cell cycle arrest of rat myocardial and human embryonic kidney cells in G2 phase. These results suggest that TBX20 may serve a functional role in cardiomyocyte proliferation by regulating cyclin $B 1$ and $P 27$ expression during heart morphogenesis. Furthermore, increased expression of GATA4 was observed following inhibition of TBX20 in the same cell lines, which may affect the maturation and differentiation of cardiomyocytes in vivo and lead to cardiac hypertrophy observed in CHD patients. 

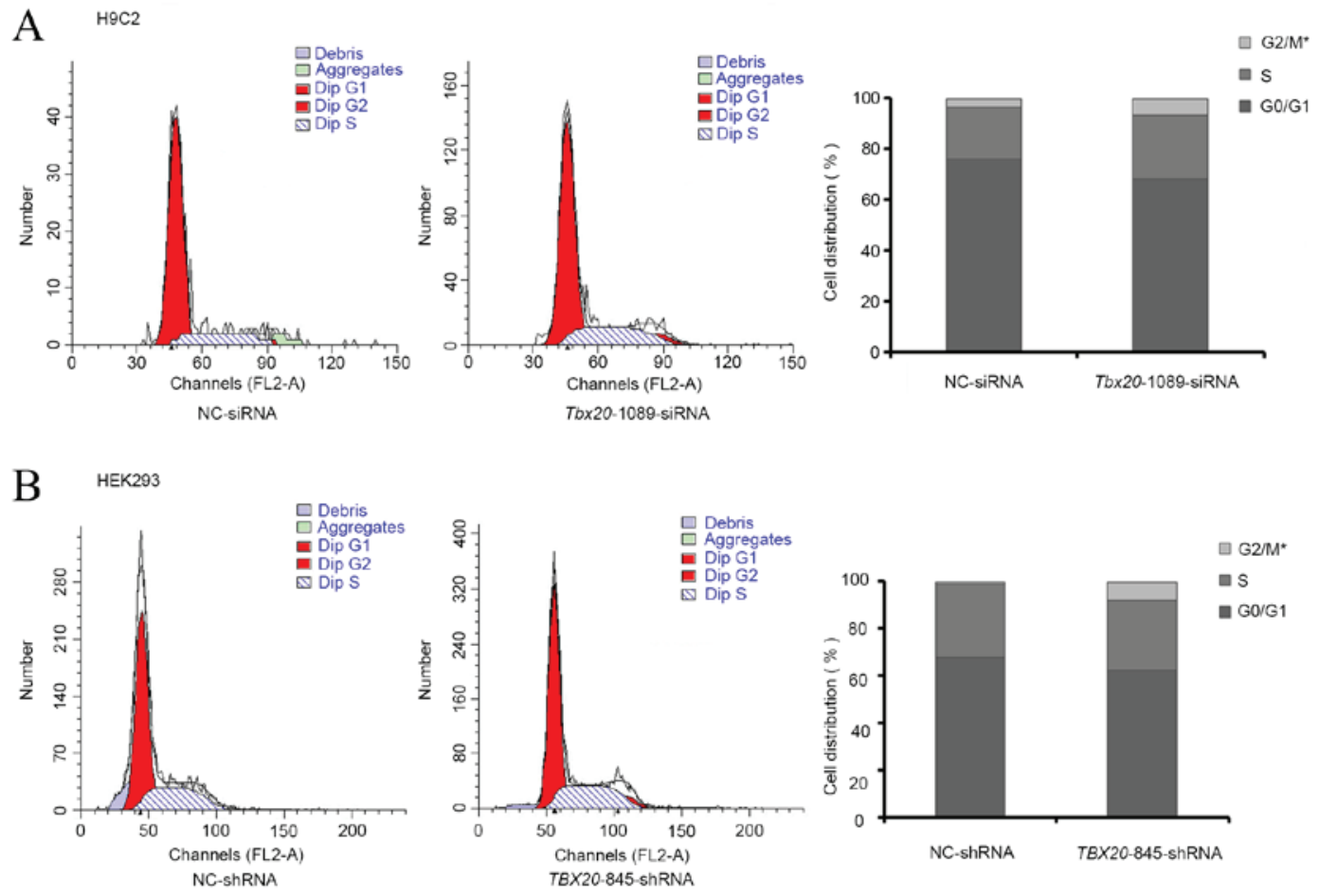

$\mathrm{C}$

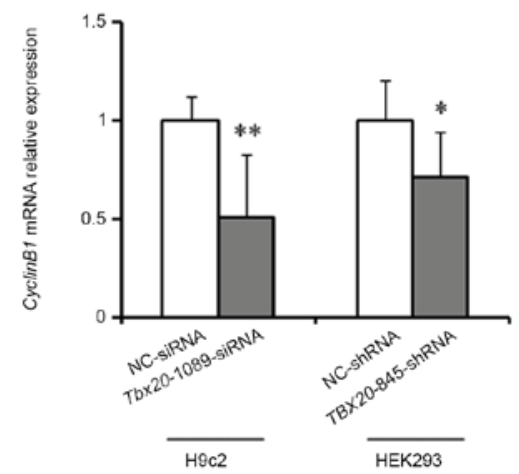

$\mathrm{E}$

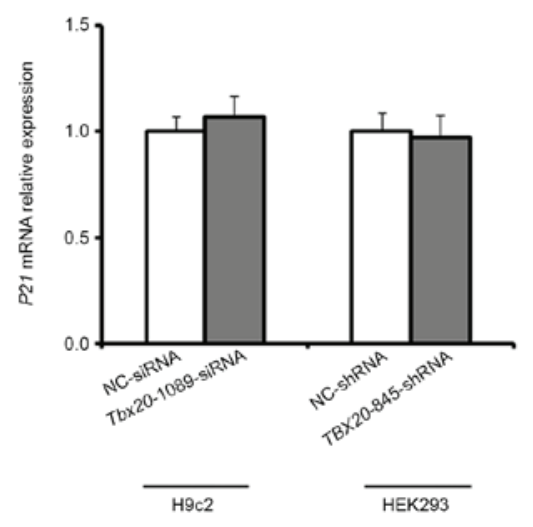

$\mathrm{D}$

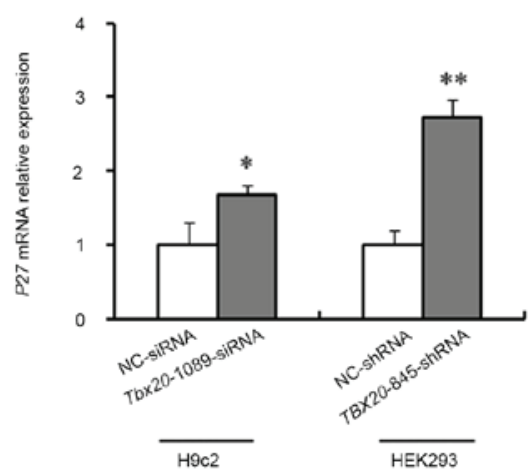

$\mathrm{F}$

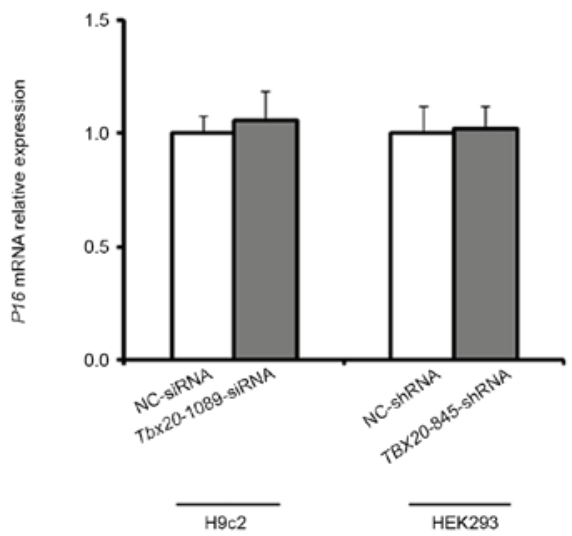

Figure 5. TBX20 inhibition arrests the cell cycle at G2 phase in H9c2 and HEK293 cells. Cell cycle distribution analysis of (A) H9c2 following transfection with Tbx20-1089-siRNA and NC-siRNA, and (B) HEK293 cells following transfection with TBX20-845-shRNA and NC-shRNA. The mRNA expression levels of (C) cyclin B1, (D) P27, (E) P21, and (F) P16 in H9c2 cells following transfection of Tbx20-1089-siRNA and NC-siRNA controls, and HEK293 cells following transfection of TBX20-845-shRNA and NC-shRNA controls. ${ }^{*} \mathrm{P}<0.05$ and ${ }^{* *} \mathrm{P}<0.01$ vs. controls. TBX20, T-box 20; siRNA, small-interfering RNA; shRNA, short-hairpin RNA; NC, normal control; P27, cyclin-dependent kinase inhibitor (CDKI) 1B; P21, CDKI1A; P16, CDKI2A.

We hypothesize that the inhibition of TBX20 expression alters normal development of the heart and leads to the occurrence of CHDs, and that a role is played by TBX2O in heart development. 
A

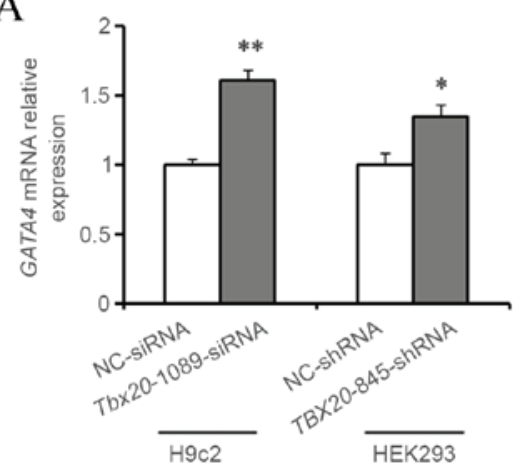

B

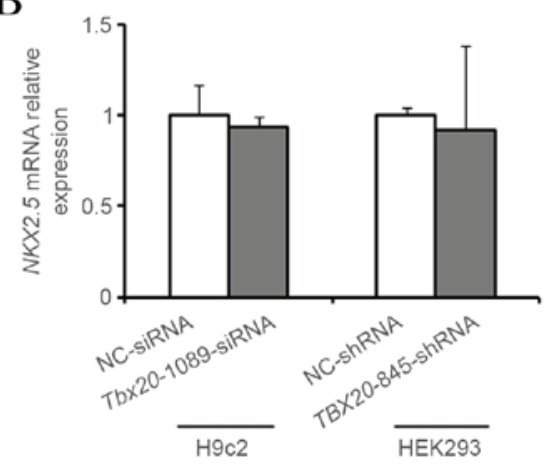

Figure 6. TBX20 inhibition upregulates GATA4 mRNA expression in H9c2 and HEK293 cells. The mRNA expression levels of (A) GATA4 and (B) NKX2-5 in H9c2 cells following transfection with Tbx20-1089-siRNA and NC-siRNA controls, and HEK293 cells following transfection with TBX20-845-shRNA and NC-shRNA controls. " $\mathrm{P}<0.05$ and ${ }^{* *} \mathrm{P}<0.01$ vs. controls. TBX20, T-box 20; GATA4, GATA binding protein 4; NKX2-5, NK2 homeobox 5; siRNA, small-interfering RNA; shRNA, short-hairpin RNA; NC, normal control.

\section{Acknowledgements}

The present study was supported by the National Natural Science Foundation of China (grant no. 81070131) and the Program for Liaoning Excellent Talents in University (grant no. LJQ2012069).

\section{References}

1. Hoffman JI and Kaplan S: The incidence of congenital heart disease. J Am Coll Cardiol 39: 1890-1900, 2002.

2. van der Linde D, Konings EE, Slager MA, Witsenburg M, Helbing WA, Takkenberg JJ and Roos-Hesselink JW: Birth prevalence of congenital heart disease worldwide: A systematic review and meta-analysis. J Am Coll Cardiol 58: 2241-2247, 2011.

3. Thienpont B, Mertens L, de Ravel T, Eyskens B, Boshoff D, Maas N, Fryns JP, Gewillig M, Vermeesch JR and Devriendt K: Submicroscopic chromosomal imbalances detected by array-CGH are a frequent cause of congenital heart defects in selected patients. Eur Heart J 28: 2778-2784, 2007.

4. Corrigan N, Brazil DP and McAuliffe F: Fetal cardiac effects of maternal hyperglycemia during pregnancy. Birth Defects Res A Clin Mol Teratol 85: 523-530, 2009.

5. Gong LG, Qiu GR, Jiang H, Xu XY, Zhu HY and Sun KL: Analysis of single nucleotide polymorphisms and haplotypes in HOXC gene cluster within susceptible region $12 q 13$ of simple congenital heart disease. Zhonghua Yi Xue Yi Chuan Xue Za Zhi 22: 497-501, 2005.

6. Srivastava D: Making or breaking the heart: From lineage determination to morphogenesis. Cell 126: 1037-1048, 2006.

7. Cai CL, Zhou W, Yang L, Bu L, Qyang Y, Zhang X, Li X, Rosenfeld MG, Chen J and Evans S: T-box genes coordinate regional rates of proliferation and regional specification during cardiogenesis. Development 132: 2475-2487, 2005.

8. Singh MK, Christoffels VM, Dias JM, Trowe MO, Petry M, Schuster-Gossler K, Bürger A, Ericson J and Kispert A: Tbx20 is essential for cardiac chamber differentiation and repression of Tbx2. Development 132: 2697-2707, 2005.

9. Stennard FA, Costa MW, Lai D, Biben C, Furtado MB, Solloway MJ, McCulley DJ, Leimena C, Preis JI, Dunwoodie SL, et al: Murine T-box transcription factor Tbx20 acts as a repressor during heart development, and is essential for adult heart integrity, function and adaptation. Development 132: 2451-2462, 2005.

10. Takeuchi JK, Mileikovskaia M, Koshiba-Takeuchi K, Heidt AB, Mori AD, Arruda EP, Gertsenstein M, Georges R, Davidson L, Mo R, et al: Tbx20 dose-dependently regulates transcription factor networks required for mouse heart and motoneuron development. Development 132: 2463-2474, 2005.

11. Qian L, Mohapatra B, Akasaka T, Liu J, Ocorr K, Towbin JA and Bodmer R: Transcription factor neuromancer/TBX20 is required for cardiac function in Drosophila with implications for human heart disease. Proc Natl Acad Sci USA 105: 19833-19838, 2008.
12. Kirk EP, Sunde M, Costa MW, Rankin SA, Wolstein O, Castro ML, Butler TL, Hyun C, Guo G, Otway R, et al: Mutations in cardiac T-box factor gene TBX20 are associated with diverse cardiac pathologies, including defects of septation and valvulogenesis and cardiomyopathy. Am J Hum Genet 81: 280-291, 2007.

13. Liu C, Shen A, Li X, Jiao W, Zhang X and Li Z: T-box transcription factor TBX20 mutations in Chinese patients with congenital heart disease. Eur J Med Genet 51: 580-587, 2008.

14. Posch MG, Gramlich M, Sunde M, Schmitt KR, Lee SH, Richter S, Kersten A, Perrot A, Panek AN, Al Khatib IH, et al: A gain-of-function TBX20 mutation causes congenital atrial septal defects, patent foramen ovale and cardiac valve defects. J Med Genet 47: 230-235, 2010.

15. Pan Y, Geng R, Zhou N, Zheng GF, Zhao H, Wang J, Zhao CM, Qiu XB, Yang YQ and Liu XY: TBX20 loss-of-function mutation contributes to double outlet right ventricle. Int J Mol Med 35: 1058-1066, 2015

16. Chen J, Sun F, Fu J and Zhang H: Association of TBX20 gene polymorphism with congenital heart disease in Han Chinese neonates. Pediatr Cardiol 36: 737-742, 2015.

17. Shen T, Aneas I, Sakabe N, Dirschinger RJ, Wang G, Smemo S, Westlund JM, Cheng H, Dalton N, Gu Y, et al: Tbx20 regulates a genetic program essential to adult mouse cardiomyocyte function. J Clin Invest 121: 4640-4654, 2011.

18. Livak KJ and Schmittgen TD: Analysis of relative gene expression data using real-time quantitative PCR and the 2 (-Delta Delta C (T)) Method. Methods 25: 402-408, 2001.

19. Hammer S, Toenjes M, Lange M, Fischer JJ, Dunkel I, Mebus S, Grimm CH, Hetzer R, Berger F and Sperling S: Characterization of TBX20 in human hearts and its regulation by TFAP2. J Cell Biochem 104: 1022-1033, 2008.

20. Kubben FJ, Peeters-Haesevoets A, Engels LG, Baeten CG, Schutte B, Arends JW, Stockbrügger RW and Blijham GH: Proliferating cell nuclear antigen (PCNA): A new marker to study human colonic cell proliferation. Gut 35: 530-535, 1994.

21. Stennard FA and Harvey RP: T-box transcription factors and their roles in regulatory hierarchies in the developing heart. Development 132: 4897-4910, 2005.

22. Chakraborty S and Yutzey KE: Tbx20 regulation of cardiac cell proliferation and lineage specialization during embryonic and fetal development in vivo. Dev Biol 363: 234-246, 2012.

23. Shelton EL and Yutzey KE: Tbx20 regulation of endocardial cushion cell proliferation and extracellular matrix gene expression. Dev Biol 302: 376-388, 2007.

24. Tang L, Zhang Y, Pan H, Luo Q, Zhu XM, Dong MY, Leung PC, Sheng JZ and Huang HF: Involvement of cyclin B1 in progesterone-mediated cell growth inhibition, G2/M cell cycle arrest and apoptosis in human endometrial cell. Reprod Biol Endocrinol 7: 144, 2009.

25. Paruthiyil S, Cvoro A, Tagliaferri M, Cohen I, Shtivelman E and Leitman DC: Estrogen receptor $\beta$ causes a G2 cell cycle arrest by inhibiting CDK1 activity through the regulation of cyclin B1, GADD45A and BTG2. Breast Cancer Res Treat 129: 777-784, 2011.

26. Yadav V, Sultana S, Yadav J and Saini N: Gatifloxacin induces $\mathrm{S}$ and $\mathrm{G} 2$-phase cell cycle arrest in pancreatic cancer cells via p21/p27/p53. PloS One 7: e47796, 2012. 
27. Mitrea DM, Yoon MK, Ou L and Kriwacki RW: Disorder-function relationships for the cell cycle regulatory proteins p21 and p27. Biol Chem 393: 259-274, 2012.

28. Lee Y, Shioi T, Kasahara H, Jobe SM, Wiese RJ, Markham BE and Izumo S: The cardiac tissue-restricted homeobox protein $\mathrm{Csx} / \mathrm{Nkx} 2.5$ physically associates with the zinc finger protein GATA4 and cooperatively activates atrial natriuretic factor gene expression. Mol Cell Biol 18: 3120-3129, 1998

29. Sepulveda JL, Vlahopoulos S, Iyer D, Belaguli $N$ and Schwartz RJ: Combinatorial expression of GATA4, Nkx2-5, and serum response factor directs early cardiac gene activity. J Biol Chem 277: 25775-25782, 2002

30. Vincentz JW, Barnes RM, Firulli BA, Conway SJ and Firulli AB: Cooperative interaction of $\mathrm{Nkx} 2.5$ and Mef2c transcription factors during heart development. Dev Dyn 237: 3809-3819, 2008.

31. Snyder M, Huang XY and Zhang JJ: Stat3 directly controls the expression of Tbx5, Nkx2.5, and GATA4 and is essential for cardiomyocyte differentiation of P19CL6 cells. J Biol Chem 285 23639-23646, 2010.

32. Schlesinger J, Schueler M, Grunert M, Fischer JJ, Zhang Q, Krueger T, Lange M, Tönjes M, Dunkel I and Sperling SR: The cardiac transcription network modulated by Gata4, Mef2a, Nkx 2.5, Srf, histone modifications and microRNAs. PLoS Genet 7: e1001313, 2011.

33. Chen Y and Cao X: NFAT directly regulates Nkx2-5 transcription during cardiac cell differentiation. Biol Cell 101: 335-349, 2009.

34. Zhao R, Watt AJ, Battle MA, Li J, Bondow BJ and Duncan SA Loss of both GATA4 and GATA6 blocks cardiac myocyte differentiation and results in acardia in mice. Dev Biol 317: 614-619, 2008.
35. Pu WT, Ishiwata T, Juraszek AL, Ma Q and Izumo S: GATA4 is a dosage-sensitive regulator of cardiac morphogenesis. Dev Biol 275: 235-244, 2004.

36. Oka T, Maillet M, Watt AJ, Schwartz RJ, Aronow BJ, Duncan SA and Molkentin JD: Cardiac-specific deletion of Gata4 reveals its requirement for hypertrophy, compensation, and myocyte viability. Circ Res 98: 837-845, 2006.

37. Guner-Ataman B, Paffett-Lugassy N, Adams MS, Nevis KR, Jahangiri L, Obregon P, Kikuchi K, Poss KD, Burns CE and Burns CG: Zebrafish second heart field development relies on progenitor specification in anterior lateral plate mesoderm and nkx2.5 function. Development 140: 1353-1363, 2013.

38. Zhao L, Ju D, Gao Q, Zheng X and Yang G: Over-expression of $\mathrm{Nkx} 2.5$ and/or cardiac $\alpha$-actin inhibit the contraction ability of ADSCs-derived cardiomyocytes. Mol Biol Rep 39: 2585-2595, 2012.

39. Liu H, Harris TM, Kim HH and Childs G: Cardiac myocyte differentiation: The Nkx2.5 and Cripto target genes in P19 clone 6 cells. Funct Integr Genomics 5: 218-239, 2005

40. Yamak A, Temsah R, Maharsy W, Caron S, Paradis P, Aries A and Nemer M: Cyclin D2 rescues size and function of GATA4 haplo-insufficient hearts. Am J Physiol Heart Circ Physiol 303: H1057-H1066, 2012.

41. Laforest B and Nemer M: GATA5 interacts with GATA4 and GATA6 in outflow tract development. Dev Biol 358: 368-378, 2011. 